\title{
Disbelief Is a Distinct Doxastic Attitude
}

\section{J. A. Smart ${ }^{1}$}

\begin{abstract}
While epistemologists routinely employ disbelief talk, it is not clear that they really mean it, given that they often equate disbelieving $p$ with believing $\neg p$. I argue that this is a mistake-disbelief is a doxastic attitude of rejection and is distinct from belief (and withholding). I first clarify this claim and its opposition, then show that we must distinguish disbelieving $p$ from believing $\neg p$ in order to account for the fact that we continue to hold doxastic attitudes toward propositions that we reject. After defending this argument against some possible objections, I examine several cases that reveal disbelieving $p$ to be not only non-identical to believing $\neg p$, but independent of that attitude as well. Finally, I sketch some immediate and potential consequences of recognizing disbelief as a distinct doxastic attitude, particularly for work on epistemic rationality.
\end{abstract}

Keywords Disbelief · Doxastic attitudes · Belief · Withholding · Epistemic Rationality

\section{Introduction}

I argue that, in addition to belief and withholding, there is a distinct, third doxastic attitude, ${ }^{2}$ that of disbelief. Call this the Distinct Attitude Thesis.

Readers may be forgiven for thinking this thesis in need of no defense. Epistemologists do routinely include disbelief in their presentations of the doxastic attitudes. For example, in his introductory text on epistemology, Richard Feldman says that, "when you consider a statement, you can adopt

${ }^{1}$ joshuasmart@gmail.com. Ohio State University, Columbus, OH, USA.

2 Throughout, this term refers to "outright" doxastic attitudes, as opposed to degrees of belief or confidence or to credences (though these make an appearance in $\S 3.2)$. 
any of three attitudes toward it: belief, disbelief, or suspension of judgment" (Feldman 2003, 13). ${ }^{3}$ And John Turri cites philosophers from Sextus Empiricus to Ernest Sosa as endorsing the view, Triad, that "there are only three doxastic attitudes - belief, disbelief, and withholding" (2012, p. 355).

Certainly Triad captures a common way that epistemologists talk about doxastic attitudes, but if it is understood as a substantive claim about their nature, then it does not seem to be nearly so popular. ${ }^{4}$ Often, when the three putative attitudes are introduced, the author goes on to make an aside indicating that 'disbelief', in fact, simply refers to a subset of beliefs. For instance, Michael Bergmann lists the doxastic attitudes as, "believing $p$, disbelieving $p$ (i.e., believing $p$ is false), and withholding $p^{\prime \prime}$ (Bergmann $2005,420)$. In a similar vein, Jack Spencer stipulates that, "an agent disbelieves that $p$ just if that agent believes that $\neg p^{\prime \prime}$ (Spencer 2016, 512), and Michael Pace identifies the two non-belief doxastic attitudes as withholding and "disbelieving p (i.e. believing not-p)" (Pace 2010, 252). ${ }^{5}$ In fact, this sort of equivalence is mundane enough that some authors simply switch between "disbelieve $p$ " and "believe $\neg p$ " without comment. ${ }^{6}$ Thus, in her discussion of suspended judgment, Jane Friedman notes that, while epistemologists often talk of suspension as "some third thing" in addition to belief and disbelief, "If a $p$-disbelief is nothing more than a $\neg$ p-belief (which is a fairly standard assumption in this context), then... [it] is really only a second thing" (2013b, p. 166 n. 2).

Let's use the label Negated Content Approach to cover this "fairly standard assumption" and various ways of fleshing it out. \$2 clarifies this

\footnotetext{
${ }^{3}$ We will not draw any distinctions among withholding (belief or judgment), suspension (of belief or judgment), or agnosticism. (See also n. 9.)

${ }^{4}$ In conversation, Turri has said that he was thinking of the substantive claim, but that given that his arguments do not depend on it, his statement of the traditional view can reasonably be read as also covering the Negated Content Approach discussed below.

${ }^{5}$ I take $\neg p$, it is false that $p$, it is not the case that $p$, etc. to be equivalent, and we will not distinguish among them, except in \$5.3, when considering the possibility of holding distinct attitudes toward $\neg p$ and $p$ is false.

${ }^{6}$ For example, (Hattiangadi 2019), (Littlejohn 2018), (McCain 2014), (Titelbaum 2015).
} 
approach, as well as the Distinct Attitude Thesis and the standard picture of doxastic attitudes with which we will be working. One upshot here is that, on that standard picture, the Negated Content Approach and Distinct Attitude Thesis seem to be the only games in town. $\$ 3$ provides the Distinct Object Argument in favor of the latter over the former, and $\S 4$ considers and rejects the Ipso Facto Response to that argument. \$5 then argues for a strong version of the Distinct Attitude Thesis on which disbelieving $p$ is not merely non-identical to believing $p$, but independent of that attitude as well. Finally, $\$ 6$ briefly explores some potential upshots of the Distinct Attitude Thesis, particularly with respect to epistemic rationality.

\section{Setup}

\subsection{Doxastic attitudes}

The doxastic attitudes are a class of cognitive propositional attitudes. Typically, that class is defined by giving its extension - standardly, belief, disbelief, and withholding - but saying a little more will be helpful for setting up the discussion below. We can do so by taking as our starting point that belief is the archetypical doxastic attitude (as the root dox-suggests). Here, we needn't commit ourselves to any detailed metaphysics of belief. What is relevant for our purposes is that belief is the cognitive attitude of acceptance. Specifically, it is the attitude of committed acceptance. So, belief that $p$ goes beyond mere inclination toward, partial, or tentative acceptance of $p$.

Of course, there are many propositions that we don't believe. Often this is because we hold no attitude toward them at all. Before composing this sentence, I held no attitude toward the proposition Socrates died before all living dogs were born, because it had simply never crossed my mind. Sometimes, however, we hold no attitude toward a proposition despite having a certain sort of awareness of it. Were I to flip through an advanced physics textbook, I would doubtless find many sentences employing concepts that I do not understand. In such a case, I am aware that the sentence expresses a proposition, but lack the right sort of cognitive relationship to that 
proposition for it to be the object of a doxastic attitude for me. A label will be helpful here, so let us say that $S$ entertains $p$ whenever $S$ is in the necessary cognitive relationship to $p$ to have an attitude toward it. ${ }^{7}$

Given all this, it is a fairly straightforward matter to fill out the standard picture of doxastic attitudes. If one does not believe $p$, then one does not accept it, but if one nevertheless entertains $p$, then that non-acceptance is attitudinal (i.e. it is not in virtue of failing to have any doxastic attitude toward $p$ whatsoever). This non-acceptance can be committal-one can (fully) reject $p$-or it can be non-committal-one can be neutral with respect to $p$-and these possibilities correspond to the standard non-belief doxastic attitudes: disbelief and withholding, respectively. ${ }^{8}$

The discussion of doxastic attitudes above has referred to disbelief, however this is only for the sake of simplicity. The general acceptance-rejection-neutrality picture of doxastic attitudes is fairly standard in epistemology, and, considered in those broad strokes, it should be acceptable to disbelief deniers and defenders alike. There are, of course, those who reject that picture. Some authors take (outright) doxastic attitudes to reduce to credences, ${ }^{9}$ and on eliminativism, disbelief, belief, and withholding all go down the same drain. ${ }^{10}$ Importantly, however, we will set aside these (and other) radically revisionary views. Our question is whether we can do

7 This is less than ideal, as 'entertains' normally indicates a certain sort of mental activity. On our stipulative use, however, it does not imply that the agent consciously considers $p$. One entertains $p$ whenever one is in a position to believe $p$ (whether by holding an occurrent or dispositional belief that $p$ ), whatever relationship that entails.

8 The neutrality ascribed to withholding here is broad, covering anything between full rejection and full acceptance. (Compare Roderick Chisholm's (1976) explication of withholding $h$ as "not accepting $h$ and not accepting $\neg h$ " (p. 27).) Some authors take withholding to require something in addition to this broad neutrality (e.g. Friedman (2013b)) and/or propose additional neutral attitudes (e.g. Turri (2012) and (McGrath 2020), though McGrath's additions are non-doxastic). These differences will not matter below, given the choice of cases and our focus on disbelief

${ }^{9}$ Cf. (Leitgeb 2013).

${ }^{10}$ Cf. (Churchland and Churchland 1998). 
without disbelief while maintaining this traditional understanding of the doxastic attitudes.

\subsection{The Distinct Attitude Thesis and the Negated Content Approach}

Another way of putting the question of this paper is this. Once we have accepted the standard picture of doxastic attitudes sketched above, should we take its references to disbelief to be eliminable?

According to the Distinct Attitude Thesis, we should not. On that view, when one rejects $p$, it is in virtue of holding the purely negative attitude toward $p$ that is not identical to any attitude of acceptance (or neutrality) one might hold. It is to this distinct attitude that our disbelief talk refers.

According to the denier, this disbelief talk is merely a convenient shorthand-strictly speaking, there is no such purely negative attitude. As we have seen, the Negated Content Approach eliminates disbelief by paraphrasing "disbelieves $p$ " as "believes $\neg p$ " (and mutatis mutandis for cognates).

This basic idea is clear, as far as it goes, but it only goes as far as one might expect from scattered parenthetical comments. In particular, it leaves open the question of what to say about $\neg p$-disbeliefs. If, for such comments, we take $p$ to be a fully general propositional variable, then they would have it that $\neg p$-disbeliefs are disguised $\neg \neg p$-beliefs. While that is the normal way to read ' $p$ ' in philosophical writing, it has, for the Negated Content Approach, the prima facie implausible consequence that we routinely form double-negation beliefs. ${ }^{11}$ It certainly does not seem that we always do, and, moreover, it does not seem that we always can. At the very least, children surely pass through a stage where they are able to grasp

11 Here, I am setting aside the Lewis/Stalnaker view of content. In its simplest form, at least, there is no distinction between a $\neg \neg p$-belief and a $p$-belief, since $\neg \neg p$ and $p$ are true in the same set of possible worlds While I attempt to remain as metaphysically neutral as possible, I take this simple version of the view to be sufficiently problematic and unpopular to safely ignore. An investigation into whether and how the points of this subsection might be made on more sophisticated versions would take us too far afield. (Thanks to Declan Smithies for suggesting this clarification.) 
(singly) negated propositions and accept or reject them, but fail to understand double negation. Such agents' rejection of any $\neg p$ could not, therefore, consist in believing $\neg \neg p .12$

In fact, I suspect that most disbelief deniers would not endorse this strict reading of the Negated Content Approach. I think it is more likely that they would take statements equating disbelief that $p$ with belief that $\neg p$ to imply a sort of symmetrical $p / \neg p$ relationship, such that rejection of either consists in believing the other. This understanding is certainly more intuitive. Our everyday reasoning rarely involves double negation, but we do often debate between the members of $p / \neg p$ pairs. Still, not all of our reasoning is of the everyday sort, and I am skeptical of the claim that we always immediately form a $p$-belief when we reject $\neg p$, especially in theoretical contexts. For instance, an intuitionist like Michael Dummett might reject $\neg p$ and accept $\neg \neg p$, yet consider it an open question whether $p$, one that he might investigate despite being settled on the question of whether $\neg p .13,14$

There is, of course, a third possible interpretation of statements equating $p$-disbelief to $\neg p$-belief. It is to take the relevant $p / \neg p$-relationship to be

12 There is a more general graspability issue as well, given that this interpretation is not restricted to rejection of singly negated propositions. Plausibly, the negation of a proposition is more complex than that proposition itself. By iterating negation, then, any (finite) agent will reach a proposition $(\neg \ldots \neg p)$ that they are able to entertain and reject, but whose negation is beyond their grasp. (This point is based on an argument for belief-credence dualism by Elizabeth Jackson (ms.).)

${ }^{13}$ This way of putting the matter is taken from (Friedman 2019). There, she argues that when one inquires one holds an "interrogative attitude" toward a question (e.g. wondering whether), and belief is an attitude that settles inquiry such that one no longer holds the question-directed attitude. Presumably, when one rejects $\neg p$ one settles a question as well, and so if the question of whether $p$ can remain open, that rejection is not in virtue of believing $p$. Importantly, however, I do not wish to rely on Friedman's account here. Rather, I take it to provide a potential explanation of the strength of the intuition to which I am appealing.

${ }^{14}$ I address questions about the possibility of conforming one's attitudes to principles of deviant logics in $\$ 4.3$ and §5.2. In this case, note that the problem stands so long as it is possible for an intuitionistic reasoner to focus on the question of whether $\neg p$ or $\neg \neg p$ such that, if their rejection of $\neg p$ consists in forming some belief, it is the belief that $\neg \neg p$. (Perhaps they would automatically form the belief that $p$ as well, but only as an inference, even if unconscious.) 
that of contradiction rather than of strict negation. Sometimes $\neg p$-disbeliefs are disguised $p$-beliefs and sometimes they are disguised $\neg \neg p$-beliefs, but either way they are still disguised beliefs, not attitudes of a distinct type. This interpretation seems the most charitable. It captures the widest range of intuitions, and no arguments below turn on whether the Negated Content Approach attempts to reduce disbeliefs to beliefs in a unified way. So, though we may occasionally refer back to the statements in $\S 1$, in what follows, we will understand the Negated Content Approach to be the view that doxastic rejection of a proposition consists in holding a belief in some contradictory of that proposition.

\subsection{Exhaustive Options}

Not only is the Negated Content Approach the most common (non-radical) proposal for eliminating disbelief, it is also, so far as I can tell, the only proposal. This may simply be because issue has not been on philosophers' radar. But in fact it is difficult to see what other approach one might take once we accept a standard picture of doxastic attitudes. Our doxastic states obviously involve rejection of propositions, and if such rejections do not consist in holding negative attitudes then it seems that they must consist in holding attitudes toward negative content. For our purposes, then, it seems that the Distinct Attitude Thesis and Negated Content Approach are the only two options on the table.

\section{The need for disbelief}

\subsection{The Distinct Object Argument}

One basic reason to think that disbelief is a distinct attitude is phenomenological. When we, say, consider some philosophical view and find it wanting, there is a sense of cognitively "pushing away" the relevant proposition(s) that is not the same as "taking in" their negations. We seem to actively take a stance of rejection. Of course, this appeal to phenomenology is not a strong argument. Further, like any reductivist position, the 
Negated Content Approach enjoys at least the theoretical advantage of simplicity. Feelings aside, if $p$-disbeliefs and $\neg p$-beliefs are both ways of rejecting $p$ and we are already committed to the existence of the latter, then the former seem to be otiose.

To see why, on the contrary, they are theoretically necessary, let's consider the case of Atheist Alfred.

\section{Atheist Alfred}

Alfred has been raised in an obscure, isolated community that studiously avoids mention of deities of any sort. One day, however, he breaks with his community and moves to the nearest city, where he happens upon a street preacher. Though surprised to learn that there is this being, God, about whom he had never heard, Alfred takes the preacher at his word, becoming a theist. Later, however, he finds out that many people don't believe that there is such a being, and, unsure who has the right of it, he becomes agnostic. Later still, a friend convinces him of the seriousness of the problem of evil, and Alfred becomes an atheist.

Alfred poses a problem for the Negated Content Approach that we can see by tracking his religious journey through his doxastic attitudes toward the proposition God exists. Initially he was theologically innocent-he did not entertain that proposition, and therefore held no attitude toward it. He then became a theist by forming the belief that God exists. Next, he became an agnostic, withholding on God exists. But what should we say about his attitude toward God exists on his conversion to atheism? He obviously does not maintain an attitude of withholding on it or revert to an attitude of believing it, but on the Negated Content Approach there are no other options. On that view, then, it appears that atheist-Alfred holds no doxastic attitude toward this proposition whatsoever. Surely this cannot be right.

Of course, this is not to say that on the Negated Content Approach atheist-Alfred holds no God-related doxastic attitudes. On that view, however, we can only say that Alfred forms the belief that God does not exist (which we can say on the Distinct Attitude Thesis as well). While this is a natural way to identify atheism, it is also a change of subject-or, rather, a change of object. After all, God exists and God does not exist are distinct 
propositions, and so God exists is not an object of the belief that God does not exist. 15

The idea that rejecting a proposition involves holding no attitude toward it (whether or not it also involves accepting the proposition's negation $^{16}$ ) is not only highly unintuitive, but, at best, in tension with traditional treatments of doxastic attitudes in epistemology. Consider standard introductions of withholding as a distinct doxastic attitude of the sort given in §2.1. Cast in terms of Alfred's case, the idea is that, innocent-Alfred and agnostic-Alfred are in different doxastic positions vis-à-vis God exists. Both lack doxastic commitment with respect to it, but since agnostic-Alfred is aware of (entertains) God exists, his lack of commitment consists in a particular stance with respect to that proposition. He holds an attitude of neutrality toward it, the attitude of withholding. Similarly, it is surely the case that atheist-Alfred's doxastic position with respect to God exists also differs from that of innocent-Alfred. Neither are doxastically positive or neutral toward God exists, but in atheist-Alfred's case this is because he takes a particular stance with respect to that proposition. He holds an attitude of rejection toward it, the attitude of disbelief.

\subsection{Support from credences}

While our focus is on outright doxastic attitudes, the Distinct Object Argument finds some support in credal considerations. Upon hearing the street preacher, Alfred clearly has a credence in God exists, and a fairly high one at that. It decreases, however, as he moves from theism to agnosticism, and

15 The point is particularly clear if we put the matter a bit more formally. On the Negated Content Approach, the only two doxastic attitudes one can hold toward a proposition, $p$, are belief $(\mathrm{B} p)$ and withholding $(\mathrm{W} p)$. Therefore, where $\mathrm{N} p$ is not having a doxastic attitude toward $p:(\neg \mathrm{B} p \wedge \neg \mathrm{W} p) \rightarrow \mathrm{N} p$. By definition, atheists such as Alfred neither believe nor withhold on $g$, God exists. $(\neg \mathrm{B} g \wedge \neg \mathrm{Wg}) \rightarrow \mathrm{Ng}$. On the Negated Content Approach, atheist-Alfred holds no attitude toward God exists. (Of course, he does believe God does not exist (B $\neg g$ ), but, obviously, $\neg g \neq g$.)

${ }^{16}$ In $\S 4$ I consider (and reject) the response that in believing $\neg p$ one holds a doxastic attitude toward $p$. For now, I simply note that the idea that doxastic rejection consists in holding an attitude of acceptance seems odd, to put it mildly. 
even further as he moves from agnosticism to atheism. It does not disappear though. Indeed, we could use Alfred's credence in God exists to track changes in the nature of Alfred's atheism. Perhaps it goes from begrudging to psychologically certain. At that point, Alfred's credence in God exists is 0 , but he still does have a credal attitude toward that proposition. Now, outright doxastic attitudes are not credences (it even seems doubtful that they correspond to precise ranges of level of credence), nevertheless, the two are clearly connected. They are two important types of belief-like attitudes that "go together" in a certain way, as illustrated by the tracking of Alfred's journey above. At the very least, then, it would be surprising to learn that atheist-Alfred continues to have a credence in God exists but no (outright) doxastic attitude toward it.

\section{The Ipso Facto Response}

\subsection{General Ipso Facto Response}

According to the Distinct Object Argument, we should reject the Negated Content Approach because it has it that atheist-Alfred holds no doxastic attitude toward God exists, when he clearly does. When I have made this argument in conversation, I have occasionally received a reply along the lines of, "Of course atheist-Alfred still holds a doxastic attitude toward God exists. He believes it is false!" Presumably, this reply is not meant to deny that God exists and it is false that God exists are distinct propositions. Rather, the idea seems to be that we do not need to appeal to a distinct attitude of disbelief because, in holding the belief that it is false that God exists, atheistAlfred ipso facto holds a doxastic attitude toward God exists. Let's call this precisification the Ipso Facto Response. ${ }^{17}$

I can somewhat feel the pull of the Ipso Facto Response, but the devil is in the details. We need clarification on what it means to "ipso facto hold a doxastic attitude," and what the basis is for thinking that atheist-Alfred

17 Thanks to Kenneth Boyce for the suggestion and significant discussion of this interpretation. 
bears this relation to God exists. Likely there are several ways of fleshing out the response. However, I think that there are two main motivating ideas or intuitions that drive these interpretations, and it will suffice to consider a few variations related to these.

\subsection{Constituent-Ipso Facto Response}

The first motivation we will consider is the idea that $p$ is "contained by," or is a constituent of, $\neg p$. That being the case, when one holds an attitude toward $\neg p$ one must also hold an attitude toward $p$ since it is in some sense cognitively "present." So, when atheist-Alfred believes God does not exist (or, better, it is false that God exists), he ipso facto holds an attitude toward God exists in virtue of the latter proposition being a constituent of the former, and this distinguishes him from innocent-Alfred, who holds neither attitude. Let's call this general approach the constituent-Ipso Facto Response.

We can see right out of the gate that the constituent-Ipso Facto Response has a serious dialectical shortcoming, given that constituency is not symmetrical. Suppose that Alfred makes a new friend who provides him with a theodicy and various arguments for God's existence, leading him to regain his theism. At this point, the proposition that Alfred (putatively) disbelieves, God does not exist, is obviously not a constituent of the proposition that he believes, God exists. ${ }^{18}$ So, even if the constituent-Ipso Facto Response worked, we would need an entirely different accounting of negation-disbeliefs (and, even if this could be provided, the whole enterprise starts to feel a bit ad hoc).

However, I do not think that the constituent approach will give us even a partially successful response to the Direct Object Argument. Consider that there does not appear to be anything special about the doxastic role of negation as opposed to that of other logical operators. ${ }^{19}$ Presumably,

${ }^{18}$ As discussed in \$2.2, the most plausible interpretation of the Negated Content Approach treats $\neg p$-disbeliefs as either disguised $p$-beliefs or disguised $\neg \neg p$-beliefs, and it is implausible to think that one believes $\neg \neg p$ whenever one believes $p$ (see n. 12).

${ }^{19}$ Excepting, perhaps, the acceptance-rejection relationship discussed in $§ 4.3$. 
then, there is a more general principle underlying this response-something along the following lines.

\section{Ipso Facto Attitude Thesis}

When $S$ holds a doxastic attitude toward a complex proposition, S ipso facto holds a doxastic attitude toward its propositional constituents. ${ }^{20}$

This thesis itself admits of two interpretations. On one, the attitude toward the constituent proposition just is the attitude toward the complex proposition - the constituent proposition is an "ipso facto object" of the attitude toward the complex proposition. On the other, the attitude toward the constituent is a distinct attitude that simply comes along for the ride-it is an "ipso facto attitude."

Importantly, the Ipso Facto Attitude Thesis enjoys some intuitive support beyond negation-belief cases. Suppose that $S$ receives testimony from an authority that $p \wedge q$. S knows nothing relevant about the subject other than that the authority has endorsed this conjunction. So, they come to believe it, but never bother with thinking about $p$ or $q$ individually. Intuitively, $S$ nevertheless holds doxastic attitudes toward these propositions. In believing $p \wedge q$, S ipso facto believes $p$ and believes $q$.

Unfortunately, however, the thesis runs into problems when we move beyond conjunction-beliefs to other sorts of attitudes or complex propositions. Suppose, for instance, that $S$ receives expert testimony that $p \rightarrow \neg q$, and comes to believe that proposition. They also believe $p$, but they have never entertained $\neg q$ (or $q$, for that matter) as an individual proposition. The Ipso Facto Attitude Thesis tells us that $S$ yet holds an attitude with only $\neg q$ as its object. But which attitude? If $\neg q$ is an ipso facto object of the belief that $p \rightarrow \neg q$, then $\neg q$ is the object of a belief $S$ holds $-S$ believes $\neg q$. That seems reasonable, but, of course $\neg q$ is itself a complex proposition, and it seems that we should therefore also say that $S$ believes $q$. Surely that can't be right. Perhaps, then, $S$ holds an ipso facto attitude toward $\neg q$. But, again, we must ask what that attitude is. True, $S$ is rationally committed to

${ }^{20}$ While complex propositions are standardly those involving two or more constituent propositions, for our purposes they include any proposition that involves a logical operator and a constituent proposition. 
believing $q$, but we should not derive an is from an ought. Not only is the motivation to do so undermined by the existence of actual agents who reject $q$ despite believing $p$ and $p \rightarrow q$, but the move would also threaten to collapse the traditional distinction between dispositional attitudes and dispositions to hold attitudes. ${ }^{21}$

At this point, the defender of ipso facto attitudes might reply that the situation appealed to above is impossible. One could not form an attitude toward a complex proposition (de re) without entertaining its propositional constituents, and this, in turn, entails holding a doxastic attitude toward them. So, the Ipso Facto Attitude Thesis was misleading in the first place. So-called "ipso facto attitudes" are really just normal attitudes that one holds due to ipso facto entertaining the constituents of complex propositions that one entertains. Which attitude one holds toward the constituent proposition(s) is simply "up to the agent" the way that it always is.

I am sympathetic to the idea that when one entertains a complex proposition, one entertains its individual constituents. If that is the case, however, it only serves to highlight a more fundamental problem for the constituent-Ipso Facto Response qua response to the Distinct Object Argument. The attitude that atheist-Alfred takes toward God exists may be "up to him," but now we must ask what that attitude could be. The defender of the response rejects disbelief as an option, but we don't want to say that atheists either believe or withhold on God exists. Perhaps it could be tempting to say that Alfred holds no particular attitude, or one that is in some sense generic or "flavorless." But it is unclear how a such an attitude could be a doxastic attitude (to what sort of epistemic norms would it be subject?), and it would also mean relinquishing the Negated Content Approach's prima facie advantage over the Distinct Attitude Thesis of greater parsimony. We might, instead, try to capture the idea of generic-ness by allowing that one could entertain $p$ without holding any doxastic attitude toward it, and saying simply that $S$ is in a doxastic state that, though non-attitudinal, is yet $p$ directed. True, such a state would be enough to distinguish atheist-Alfred from innocent-Alfred. However, that is not, by itself, enough to salvage the Ipso Facto Response. Alfred's journey indicates (and we could always

${ }^{21}$ See (Audi 1994). 
stipulate) that, at least when he is making the conversion to atheism, he is actively considering God exists. On converting, he does not bear some generic cognitive relationship to that proposition. He rejects it.

\subsection{Rejection-Ipso Facto Response}

This appeal to rejection leads us to the second (and perhaps more plausible) interpretation of the Ipso Facto Response, on which it should be understood as making the claim that belief that $\neg p$ is ipso facto an attitude toward $p$. Presumably this is not meant to deny that $p$ and $\neg p$ are distinct propositions, and we have already seen the sorts of problems that arise for positing that a belief that $\neg p$ is an attitude toward $p$ in some generic sense. The idea then seems to be the following.

\section{Ipso Facto Rejection Thesis}

When $S$ believes $\neg p$, that belief is ipso facto a doxastic attitude toward $p$ in virtue of the fact that acceptance of $\neg p$ is ipso facto rejection of $p$.

At a glance, this construal of the Ipso Facto Response does seem able to get around the considerations above (at least, when combined with the claim that entertaining a complex proposition entails entertaining its propositional constituents). On closer examination, though, it is difficult to see how it could do so without abandoning the traditional picture of doxastic attitudes that we have taken on as a working constraint. It seems just about as fundamental of an aspect of that view as there could be that holding a belief with $p$ as its object means that one accepts, not rejects, that proposition. ${ }^{22}$

That said, the Ipso Facto Rejection Thesis is not without motivation. Consider that the cognitive acts of acceptance and rejection closely mirror the linguistic acts of assertion and denial, and, in ordinary circumstances,

${ }^{22}$ It might be objected that this construal is misleading $-p$ is part of the content of a belief that $\neg p$, even if it is not the object of acceptance for that attitude. However, this is basically to take $p$ as an "ipso facto object" of belief that $\neg p$, and we have already seen the problems with that approach. (Thanks to Declan Smithies for flagging this consideration.) 
when one asserts $\neg p$ one ipso facto denies $p$. It does not seem unreasonable, then, to think that when one accepts $\neg p$ one ipso facto rejects $p$.

There are problems with appealing to this analogy, however. The need for ordinary circumstances to be in place for the ipso facto relationship between assertion and denial indicates that in such cases one should be understood as performing the distinct illocutionary acts of assertion and denial by making a single utterance, not making an assertion that is a denial. A more appropriate analogy would have belief as the analog of an utterance in virtue of which one both accepts and rejects. Belief, then, would not be an attitude of acceptance per se, but an attitude of commitment with dual valance. ${ }^{23}$ Not only is this at odds with our intuitive understanding of belief as an attitude specifically of acceptance, but it would also require overhaul of our understanding of the objects of belief. Instead of individual propositions they would have to be one or more propositional pairs. I take it that this would be a bridge too far for those who wish to maintain something resembling the traditional picture of the doxastic attitudes.

In addition, there is another problem faced not only by this Janus-Belief proposal, but the rejection-Ipso Facto Response in general. ${ }^{24}$ Consider that dialetheists provide a type of case that violates the "ordinary circumstances" constraint above, as they are perfectly happy to assert (at least some) contradictions. More to the current point, dialetheists believe contradictions. When a dialetheist both believes $p$ is true and $p$ is false, the Ipso Facto Rejection Thesis seems to have it that they both accept and reject $p$, but not even dialetheists think that is possible. ${ }^{25}$ One might reply that dialetheists are simply mistaken about their own attitudes. Perhaps they believe true contradictions exist, or even that $p$ is true and $p$ is false is an example of a true contradiction, but not contradictions themselves, as doing so (at

${ }^{23}$ At this point, of course, the rejection we are considering is not ipso facto, but we can always find a more appropriate name should the strategy prove out.

${ }^{24}$ Indeed, it is a problem for any version of the Negated Content Approach. However, its relevance is most straightforward in the context of the Ipso Facto Rejection Thesis.

${ }^{25}$ Cf. (Priest, 2008, §6.5). 
least knowingly) is impossible. ${ }^{26}$ This is dubious at best, however, and not only because it denies the claims of intelligent, carefully introspective dialetheists. Even those who strive for perfect consistency often fail to achieve it. Most of us have had the unpleasant experience of discovering that we hold contradictory beliefs. Yet, when we gain that knowledge, we do not instantly and automatically cease to hold them. The rational requirement not to simultaneously believe $p$ and $\neg p$ is a norm, not a necessity. ${ }^{27}$

Doubtless, some will remain unwilling to countenance the possibility of knowingly believing contradictions. If so, then they owe a response to this and other arguments to the contrary ${ }^{28}$ that does not depend on the view in question. Alternatively, there may a principled way to accept the possibility, but "quarantine" dialetheists (though I am highly skeptical). So, this is not a knockdown argument against the Ipso Facto Rejection Thesis, nevertheless, it does place an additional burden on the defenders of that view. We should also keep in mind that this burden is secondary. Even if it is shouldered, the fact remains that ipso facto rejection leads to a picture of belief that is not merely revisionary, but radically so. Not only does developing and defending such a picture present a greater challenge, it abandons the traditional understanding of the doxastic attitudes to the extent that it is out of bounds in the current dialectical context.

\section{A Distinction with a Difference}

\footnotetext{
${ }^{26}$ It is worth noting that even allowing for beliefs of this sort puts pressure on the defender of the Ipso Facto Rejection Thesis to reject all ipso facto attitudes. I suspect that they would be inclined to accept the most intuitive examples, such as ipso facto belief in the conjuncts of a believed conjunction. Such intuitions would seem to extend to beliefs of the form $p \wedge q$ is a true conjunction. Yet if ipso facto rejection defenders allow that the latter form yields ipso facto belief in the conjuncts, they must add, "unless the conjuncts are known to be contradictory." This seems ad hoc, and, given the small difference between belief that $p \wedge q$ and belief that $p \wedge q$ is a true conjunction, it appears more appropriate to reject ipso facto attitudes altogether.

27 This is a variation on an argument by Priest (2006, 96 - 97).

${ }^{28}$ See (Priest 2006, 96 - 97) and (Routley and Routley 1975, 211 - 212).
} 


\subsection{Independent Disbelief}

The Distinct Object Argument reveals that we need an something more than belief (or withholding) to account for the fact that we continue to hold doxastic attitudes toward propositions that we reject. We need a distinct doxastic attitude of disbelief. However, there is distinct, and then there is distinct. For all that we have said thus far, there may yet be a necessary connection of some sort between rejecting a proposition and accepting its contradictory. This section argues that, to the contrary, disbelief is a distinct doxastic attitude in the strong sense that it independent of belief. While we do routinely believe contradictories of propositions that we disbelieve, there are also cases where we do not, instead holding some other attitude toward them, or even no attitude at all.

\subsection{Disbelief and disbelief}

For a case of disbelief in both a proposition and its contradictory, let's return to the topic of intuitionistic reasoning (briefly discussed in §2), adapting an example from Michael Dummett. ${ }^{29}$ Dummett moves intuitionism from its mathematical origins into ordinary circumstances by tying it to anti-realism, a view that rejects the correspondence theory of truth in a way that allows meaningful assertions to be neither true nor false. ${ }^{30}$ Suppose that Hank is an anti-realist of this sort, and that he is considering whether it's true that Brita wasn't brave, given that she never in life faced a situation in which she was given the opportunity to act bravely or not. Eventually, he decides (justifiedly or not) that the counterfactuals relevant to such questions do not ground any truth of the matter in Brita's case. So, Hank accepts it isn't true that Brita wasn't brave. Naturally enough, he rejects Brita wasn't brave, but given his anti-realist reasoning, he also rejects Brita was

29 See (Dummett 1978, 14 - 16). While Dummett's original example is given in terms of assertion and denial, rather than belief and disbelief, he explicitly introduces it by noting that even those who reject the correspondence theory of truth often remain realist in their thinking.

30 The details of this connection needn't concern us here. 
brave. In the end, then, Hank disbelieves both Brita was brave and a contradictory of that proposition.

As with dialetheism in $\S 4.3$, some will no doubt be skeptical that agents can conform their attitudes to intuitionistic principles. However, I find that difficult to buy in cases like Hank's. One might, of course, argue that, if it really were not the case that "Brita was brave" is either true or false, then it is meaningless, and it could not be that Hank has any doxastic attitude whatsoever with Brita was brave as its content. But, so long as it actually is the case that Hank can hold a doxastic attitude toward Brita was brave, the point stands. Suppose Hank were raised in an intuitionist cult, cutting his teeth on anti-realist claims, and being fed a steady diet of arguments that claims about bravery and the like needn't be either true or false. Surely, in such a scenario, when Hank decides that "Brita is brave" is such a claim, he does not continue to withhold on or come to believe either Brita was brave or Britta wasn't brave.

\subsection{Disbelief and withholding}

For an example of believing a proposition while withholding on its contradictory, let's look to a case that bears some similarities with Hank's, but without the non-standard commitments. Suppose that Elle is an intelligent, though philosophically untrained student who comes across B, the sentence, "Buffalo buffalo buffalo." It takes her a second to process, and she thinks, "Wait, is that sentence true?", but once she figures out the meaning she rejects that idea-she disbelieves $B$ is true. However, Elle then remembers a philosopher friend once telling her that nonsense sentences can't be true or false. "Buffalo buffalo buffalo" certainly sounds like nonsense, but she also has a vague recollection of there being different kinds of nonsense sentences and wonders whether $B$ is of the neither-true-nor-false sort. Elle, therefore, disbelieves $B$ is true while withholding on $B$ is false.

A potential worry here concerns the rendering of the propositions Elle entertains as B is true/false, rather than as buffalo buffalo buffalo and buffalo do not buffalo buffalo. Perhaps the lesson of Elle's case is that we should not 
have been so quick to identify belief that $p$ is false with belief that $\neg p .{ }^{31}$ Elle might withhold on $B$ is false, but believe $\neg$ ( $B$ is true).

While I am sympathetic to the idea that one can hold distinct attitudes toward $p$ is false and $\neg p, 32$ I don't think that this is enough to salvage the Negated Content Approach. The problem is that doing so requires grasping $p$ is false and $\neg p$ as distinct propositions. If Elle were a philosopher or a logician then, when she rejects $B$ is true she might form the belief $\neg$ ( $B$ is true) without forming the belief that $B$ is false. But she is not, and it is reasonable to assume (or stipulate) that she does not make this distinction.

There is another possibility along these lines as well. Presumably, if we are distinguishing belief that $p$ is false from belief that $\neg p$, then those who defend the Negated Content Approach would endorse an amendment that allows for putative disbeliefs to be either $\neg p$-beliefs or $p$ is false-beliefs. So, perhaps Elle's rejection of $B$ is true consists in believing it is false that $B$ is true. But, again, this does not seem like an apt description in Elle's case. When she comes to understand what B means, she takes a (negative) stance on her question, "Is that sentence true?" It is no more reasonable to take her answer to be "'That sentence is true' is false" than to take her initial question to be "Is "That sentence is true' true?"

\subsection{Disbelief alone}

The last independence possibility is that one disbelieves $p$ without entertaining $\neg p$, and therefore never holding a doxastic attitude toward it). Perhaps surprisingly, this is, I think, the commonest type of independent disbelief case. Take Riley for example. Riley is describing the car show he recently attended to a friend, and mentions that there were two Corvettes, a ' 65 and a '67. His friend asks if one was red, and when Riley says yes, the friend asks, "Was it the ' 65 or ' 67 that was red?" Here, Riley doesn't immediately recall, and has to search his memory. Eventually he brings to mind

31 See n. 5.

32 This might be the case if, as is not implausible, the objects of propositional attitudes are actually something more fine-grained than propositions, such as Fregean senses. 
an image of the two side-by-side, the bright blue '65 and the rich cherry '67. "I remember!" he says, "it was the '67 that was red."

Consider Riley's searching of his memory. It was prompted by the question posed to him, and so he was entertaining the pair of propositions the red Corvette was the '65 (r65) and the red Corvette was the ' 67 (r67). When he then recalled the appearance of the cars, he formed the belief that $r 67$. Of course, he did not simply "forget about" the proposition r65 at that point. It was one of two mutually exclusive options on which he was focused, so answering the question before his mind involved rejecting that proposition as well as accepting its alternative-Riley formed the disbelief that $r 65$. However, there is no reason to think that he also formed the belief that $\neg$ r65. That was not the contrast with $r 65$ that he was considering as part of his internal inquiry, So, while he will be highly disposed to believe $\neg r 65$, he won't actually form that belief unless prompted. ${ }^{33}$

While paradoxes and dubious cases of nonsense do not play a major role in most of our lives, Riley's experience is surely a familiar one. Many of the questions that we consider are posed as choices among multiple positive options. We respond by accepting one and rejecting the others, but do not usually bother to entertain the relevant contradictories when we do so. There is no need, and besides, we are often focused on taking an action on the basis of the belief formed (even if, as in Riley's case, this is just informing someone else). Far from exotic, then, independent disbeliefs are a routine feature of our cognition.

\section{Some Upshots of the Distinct Attitude Thesis}

\subsection{Consequences for withholding and evidence}

Before closing, it is worth considering some upshots of the Distinct Attitude Thesis - particularly the strong, independence version-beyond the status of disbelief. The most immediate of these is that it has consequences

33 Riley would also form a contrary color-belief to ' 65 , but it would be that the '65 Corvette was blue, since the blueness of the car would be a highly salient color-feature of his mental image, while the non-redness would not. 
for our understanding of withholding. Standardly, withholding on $p$ is contrasted with believing either $p$ or $\neg p$. These same attitudes, of course, contrast with neutrality on $\neg p$, and so to form either belief is taken to entail giving up withholding on both propositions. On the Distinct Attitude Thesis, however, withholding on $p$ contrasts with the non-neutral options of belief or disbelief that $p$, and withholding on $\neg p$ contrasts with belief or disbelief that $\neg p$. Indeed, Elle's case reveals the independence of withholding on $p$ from withholding on $\neg p$ just as much as that of disbelieving $p$ from believing $\neg p$.

This picture of the doxastic attitudes has epistemological ramifications as well. Consider that evidence (at least first-order evidence) always favors some committal attitude and disfavors the contrary committal attitude. On the Negated Content Approach, one's evidence favoring belief that $p$ just is one's evidence disfavoring belief that $\neg p$. Not so on the Distinct Attitude Thesis, where the committal attitude contrary to believing $p$ is disbelieving $p$. That is not to say, of course, that when one gains evidence favoring belief that $p$ one does not gain evidence disfavoring belief that $\neg p$, but it matters that these evidential relationships are not one and the same. Suppose that $S$ receives reliable testimony, $T$, that $p$. T is evidence (for $S$ ) that directly favors believing $p$, and, as such, also directly, and in equal measure, disfavors disbelieving $p$. However, $\mathrm{T}$ only indirectly disfavors believing $\neg p$, which means that the extent to which T disfavors believing $\neg p$ can at most be equal to the extent to which it disfavors disbelieving $p$, and may be less. ${ }^{34}$ In many cases, differences along these lines will not have an effect on which attitudes are justified for an agent, but not always. For instance, they trivially make a difference in cases of testimony that one ought to disbelieve $p$, but ought not to believe $\neg p$, but let's also consider how the Distinct Attitude thesis could have further-reaching epistemological consequences.

${ }^{34}$ At least, this is the case in most situations. The point is not fully general, due to some obscure possibilities. For example, T could more strongly favor believing $\neg p$ for $S$ if an oracle has told them that if they receive any testimony about $p$, then they rationally ought to believe $\neg p$. 


\subsection{A more speculative possibility}

To see how the consequences of the Distinct Attitude Thesis might extend to more specific epistemological discussions, suppose that Coco is in a lottery case with an arbitrarily low chance of winning and an arbitrarily high payout. ${ }^{35}$ Here, her evidential support for believing my ticket is not a winner $(\neg w)$ is stronger than for almost any other belief she holds, yet many would take her to not be justified in believing that proposition.

Let's consider a particular basis for thinking that Coco is not justified in believing $\neg w$, the pragmatic encroachment view of Jeremy Fantl and Matthew McGrath (2002). They defend the following principle.

\section{PCA}

$\mathrm{S}$ is justified in believing that $\mathrm{p}$ only if $\mathrm{S}$ is rational to act as if $\mathrm{p}$.

Given the stakes of the lottery, it would be irrational for Coco to act as if her ticket is not a winner by throwing it away. On PCA, then, she is not justified in believing $\neg w$, but only in withholding on it (disbelief is obviously precluded by her evidence).

If Coco is justified in withholding on $\neg w$, then it seems obvious that she should be justified in withholding on w, my ticket is a winner. But I am not sure that this is the case. Consider that her evidence supports disbelieving $w$ to the same extreme extent that it supports believing $\neg w$, but here PCA does not come into play. It is not just that the principle does not concern disbelieving. It could not. The tie between rational action and justified belief only works because we act on beliefs about the way the world is, and the success or failure of our actions depends on the way that the world is. ${ }^{36}$ Disbeliefs, on the other hand, are rejections, not opposing representations. They are not the sort of things that we can act on, and so it does not make sense that their justification would be tied to the rationality of action in a PCA-like way.

35 Thanks to Ethan Brauer and Evan Thomas for suggesting that disbelief might be relevant to such cases.

${ }^{36}$ In the sense that I am using this phrase, one "way that the world is", is that it is not-other-ways. These are the features of the world represented by negation-beliefs. 
This lottery case is meant only to be illustrative of the potential impact of the Distinct Attitude Thesis, and I do not wish to commit myself to the analysis above. It obviously makes controversial assumptions, and I do feel a strong intuitive pull from the response that there could not be a difference in one's justification for believing $p$ and withholding on $\neg p$ because there is something incoherent about holding that pair of attitudes. This response is itself not insignificant, though. It reinforces the importance of recent discussions concerning the justificatory relationship of evidence and coherence, and even raises the possibility of a novel sort of conflict between the two. ${ }^{37}$

\section{Conclusion}

It is not uncommon for epistemologists to take rejecting $p$ to be a matter of believing the negation of its content rather than holding a negative attitude of disbelief toward $p$. The Distinct Object Argument (with support from credal considerations) shows that this is a mistake. We continue to hold doxastic attitudes (obviously, negative ones) toward propositions that we reject. We have seen that the constituent interpretation of the Ipso Facto Response to the Distinct Object Argument fails, and that the rejection interpretation, at best, fails to do so while retaining a traditional picture of the doxastic attitudes. So, we should accept that there is a distinct, negative doxastic attitude of disbelief. Moreover, this attitude is not merely nonidentical to, but independent of, negation-belief. It is possible to disbelieve $p$ while holding the attitudes of belief or withholding toward $\neg p$, or no attitude at all. And, it is this independence, in particular, that suggests ramifications for the Distinct Attitude Thesis beyond the attitudinal status of disbelief. 38

37 Recent discussion in this area (e.g. (Littlejohn 2018) and (Worsnip 2018), among others) has focused almost exclusively on "inter-level" conflicts, and especially the possibility of epistemic akrasia. In the lottery and liar cases, the relevant constraints would be first-order (e.g. Rationality requires that if one withholds on $p$, then one does not believe or disbelieve $\neg p$ ).

${ }^{38}$ I am indebted to many for helpful conversations and comments on earlier drafts of this paper, including Ethan Brauer, Liz Jackson, Matthew McGrath, Andrew 


\section{References}

Audi, Robert. 1994. "Dispositional Beliefs and Dispositions to Believe." Nous 28: 419-434.

Bergmann, Michael. 2005. "Defeaters and Higher-Level Requirements." The Philosophical Quarterly 35 (220): 419-36.

Chisholm, Roderick. 1976. Person and Object. La Salle, IL: Open Court.

Churchland, Paul M, and Patricia Smith Churchland. 1998. On the Contrary: Critical Essays, 1987-1997. Cambridge, MA: MIT Press.

Dummett, Michael. 1978. "Truth." In Truth and Other Enigmas. Cambridge, MA: Harvard University Press.

Fantl, Jeremy, and Matthew McGrath. 2002. "Evidence, Pragmatics, and Justification." The Philosophical Review 111: 67-94.

Feldman, Richard. 2003. Epistemology. Upper Saddle River, New Jersey: Prentice Hall.

Friedman, Jane. 2019. "Inquiry and Belief." Noûs 53: 296-315.

Friedman, Jane. 2013a. "Question-Directed Attitudes." Philosophical Perspectives 27: 145-74.

Friedman, Jane. 2013b. "Suspended judgment." Philosophical Studies 162: 165-181.

Hattiangadi, Anandi. 2019. "No, one should not believe all truths." Inquiry 62: 1091 - 1103.

Jackson, Elizabeth. ms. "Belief, Credence, and Graspability: Why Credences Are Not Beliefs."

Leitgeb, Hannes. 2013. "Reducing Belief Simpliciter to Degrees of Belief." Annals of Pure and Applied Logic 164: 1338-1389.

Littlejohn, Clayton. 2018. "Stop Making Sense? On a Puzzle about Rationality." Philosophy and Phenomenological Research XCVI: 257275.

McCain, Kevin. 2014. Evidentialism and Epistemic Justification. New York: Routledge.

Moon, Declan Smithies, Brian Weatherson, Evan T. Woods, and especially Kenneth Boyce. The paper has also significantly benefited from comments by several anonymous reviewers. 
McGrath, Matthew. 2020. "Being neutral: Agnosticism, inquiry and the suspension of judgment." Nous. doi:https://doi.org/10.1111/nous.12323.

Pace, Michael. 2010. "The Epistemic Value of Moral Considerations: Justification, Moral Encroachment, and James' "Will to Believe'." Nous 45: 239-268.

Priest, Graham. 2006. In Contradiction: A Study of the Transconsistent. 2. Oxford: Clarendon Press.

Routley, Richard, and Valerie Routley. 1975. "The Role of Inconsistent and Incomplete Theories in the Logic of Belief." Communication and Cognition 8: 185-235.

Spencer, Jack. 2016. "Disagreement and Attitudinal Relativism." Mind 125: 511-539.

Titelbaum, Michael G. 2015. "Rationality's Fixed Point (Or: In Defense of Right Reason)." In Oxford Studies in Epistemology 5, 253-94. Oxford: Oxford University Press.

Turri, John. 2012. "A Puzzle About Withholding." The Philosophical Quarterly (62): 355-64.

Worsnip, Alex. 2018. "The Conflict of Evidence and Coherence." Philosophy and Phenomenological Research 96 (1): 3-44. 